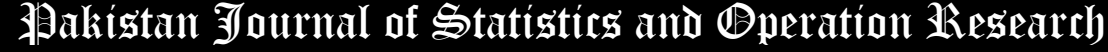

\section{The Weibull-G Poisson Family for Analyzing Lifetime Data}

\author{
Haitham M. Yousof ${ }^{1 *}$, Muhammad Mansoor ${ }^{2}$, Morad Alizadeh $^{3}$, \\ Ahmed Z. Afify ${ }^{4}$, Indranil Ghosh ${ }^{5}$ \\ * Corresponding Author \\ 1. Department of Statistics, Mathematics and Insurance, Benha University, Egypt. \\ haitham.yousof@fcom.bu.edu.eg \\ 2. Department of Statistics, The Islamia University of Bahawalpur, Bahawalpur, Pakistan. \\ 3. Department of Statistics, Persian Gulf University, Bushehr, 75169, Iran. moradalizadeh78@gmail.com \\ 4. Department of Statistics, Mathematics and Insurance, Benha University, Egypt. \\ AHMED.AFIFY@fcom.bu.edu.eg \\ 5. Department of Mathematics and Statistics, University of North Carolina Wilmington, USA. \\ jamesbond.indranil@gmail.com
}

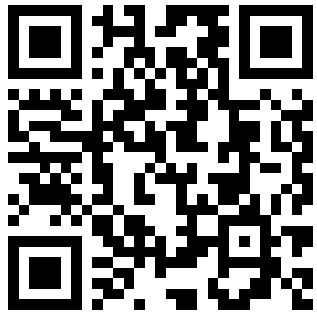

\begin{abstract}
We study a new family of distributions defined by the minimum of the Poisson random number of independent identically distributed random variables having a general Weibull-G distribution (see Bourguignon et al. (2014)). Some mathematical properties of the new family including ordinary and incomplete moments, quantile and generating functions, mean deviations, order statistics, reliability and entropies are derived. Maximum likelihood estimation of the model parameters is investigated. Three special models of the new family are discussed. We perform three applications to real data sets to show the potentiality of the proposed family.
\end{abstract}

Key Words: Weibull-G family, Entropy, Generating Function, Maximum Likelihood, Order Statistic.

Mathematical Subject Classification: 62N01; 62N02; 62E10.

\section{Introduction}

In many applied areas such as lifetime analysis, biomedical science, reliability, engineering, social sciences, finance and insurance, there is a clear need for extended forms of the classical models, i.e., new distributions which are more flexible to capture skewness and kurtosis behavior and to improve the goodness-of-fit of the generated family. Recent developments focus on new techniques by adding shape parameters to existing distributions for building classes of more flexible distributions. However, there is a clear need for further extended distributions, which are more flexible to model lifetime data in applied areas.

Several studies have suggested that Weibull distribution, an asymmetrical distribution has limitations in fitting all types of data where the topic of reliability comes into play. For example, Drobinski et al. (2015) in their study, demonstrated that in modeling wind speed data, since the Weibull distribution is heavily relied on empirical perspective rather than physical justification, it might not be a good candidate in fitting to these types of environmental data. In their study, the authors provided due justification that the Weibull model works less efficiently for wind speed data as compared to wind components data. Basu et al. (2009) studied the usefulness of the Weibull distribution in evaluating the strength distribution for brittle materials. The authors indicated that other probability models, such as normal, log-normal works better under certain reasonable circumstances. On the other hand, the Poisson distribution has its limitation as well as demonstrated by Pak-poy (1964). It is suggested in that study that the popular Poisson model for modeling road traffic problems is not recommended in some practical situations, where the variance is much 
bigger than the mean. All these above merits for finding a mixture of Weibull-G family of distribution, proposed and studied by Bourguignon et al. (2014) (after adding more flexibility to Weibull model itself) with possibly a discrete probability distribution with the same support $(0, \infty)$. This is why we considered Poisson distribution with the Weibull-G type models to capture more flexibility. We hope that our proposed model will be better in capturing several patterns of the data structure to describe appropriately the associated reliability structure, in particular to those cases where the individual Weibull-G family (a specific member) or the Poisson distribution alone might not be a good model.

The well-known generators are the following: beta-G by Eugene et al. (2002), Kumaraswamy-G by Cordeiro and de Castro (2011), exponentiated generalized-G by Cordeiro et al. (2013), generalized transmuted-G by Nofal et al. (2017), transmuted exponentiated generalized-G by Yousof et al. (2015), Kumaraswamy transmuted-G by Afify et al. (2016b), transmuted geometric-G by Afify et al. (2016a), generalized odd generalized exponential family by Alizadeh et al. (2017), exponentiated Weibull-H family by Cordeiro et al. (2017), exponentiated generalized-G Poisson family by Aryal and Yousof (2017), transmuted Weibull-G family by Alizadeh et al. (2018), Marshall-Olkin generalized-G Poisson family by Korkmaz et al. (2018b) and odd Lomax-G family by Cordeiro et al. (2019). Many other useful families and new models can be cited by Brito et al. (2017), Cordeiro et al. (2018), Altun et al. (2018a-b), Gad et al. (2019), Yousof et al. (2017a-b, 2018a-d and 2019), Hamedani et al. (2017, 2018 and 2019), Korkmaz et al. (2018a), Sen et al. (2018), Korkmaz et al. (2019), Ibrahim et al. (2019), Nascimento et al. (2019) and Ibrahim (2020a-b) and Mansour et al. (2020).

We motivate our model by considering a typical system failure in a reliability context. We envision a scenario that we will encounter a data which is a mixture of discrete and continuous type. We begin by assuming the distribution of a system consisting of $N$ independent subsystems having a zero inflated Poisson distribution. We discard the scenario that all components simultaneously will fail to work, theoretically viable but realistically not a prudent one.

Suppose $Z_{1}, \ldots, Z_{N}$ be independent identically random variable (iid) with common CDF Weibull-G and $N$ be random variable with

and define $M_{N}=\max \left(Z_{1}, \ldots, Z_{N}\right)$ then

$$
P(N=n)=\frac{1}{\exp (\theta)-1} \times \frac{\theta^{n}}{n !} \mid n=1,2, \ldots, \theta>0
$$

$$
\begin{gathered}
F(x)=\sum_{n=1}^{\infty} \operatorname{Pr}\left(M_{N} \leq x \mid N=n\right) \operatorname{Pr}(N=n) \\
=\sum_{n=1}^{\infty}\left\{\frac{1-\exp [-\theta G(x ; \alpha, \phi)]}{[\exp (\theta)-1]}\right\} \frac{1}{\exp (\theta)-1} \frac{\theta^{n}}{n !} \\
=\frac{1}{[\exp (\theta)-1]}\left\{\exp \left(\theta-\theta \exp \left\{-\left[\frac{G(x ; \phi)}{\bar{G}(x ; \phi)}\right]^{\alpha}\right\}\right)-1\right\}
\end{gathered}
$$

Equation (1) is called Weibull-G Poisson (WGP) distribution. Several new models can be generated by considering special distributions for $G(x ; \phi)$.

The corresponding PDF of (1) reduces to

$$
\begin{array}{r}
f(x ; \theta, \alpha, \phi)=\frac{\theta \alpha g(x ; \phi) G(x ; \phi)^{\alpha-1}}{[\exp (\theta)-1] \bar{G}(x ; \phi)^{\alpha+1}} \exp \left\{-\left[\frac{G(x ; \phi)}{\bar{G}(x ; \phi)}\right]^{\alpha}\right\} \\
\times \exp \left(\theta-\theta \exp \left\{-\left[\frac{G(x ; \phi)}{\bar{G}(x ; \phi)}\right]^{\alpha}\right\}\right) .
\end{array}
$$

The reliability function (rf) of $X$ is given by

$$
R(x ; \theta, \alpha, \phi)=1-\frac{1}{[\exp (\theta)-1]}\left\{\exp \left(\theta-\theta \exp \left\{-\left[\frac{G(x ; \phi)}{\bar{G}(x ; \phi)}\right]^{\alpha}\right\}\right)-1\right\},
$$

where $\theta$ and $\alpha$ are two positive shape parameters. A random variable $X$ with PDF (2) is denoted by $X \sim$ WGP $(\theta, \alpha, \phi)$.

The rest of the paper is organized as follows. In Section 2, we provide a useful mixture representation for its PDF. In Section 3, we define two special models and give some plots of their PDF's and hazard rate functions. In Section 4, we derive some of its general mathematical properties including quantile and generating functions, ordinary and incomplete moments, mean deviations, entropies, order statistics, residual and reversed residual life and stress-strength 
mode. Maximum likelihood estimation of the model parameters is addressed in Section 5. In Section 6, simulation results to assess the performance of the proposed maximum likelihood estimation procedure are discussed. In Section 7, we provide three applications to real data to illustrate the importance and flexibility of the new family. Finally, some concluding remarks are presented in Section 8.

\section{Linear representation}

In this section, we provide a useful representation for (2) using the concept of exponentiated distributions.

The WGP family density in (2) can be expressed as

The last equation can be expressed as

$$
\begin{gathered}
f(x)=\frac{\theta \alpha}{[\exp (\theta)-1]} \sum_{i=0}^{\infty} \frac{\theta^{i} g(x ; \phi) G(x ; \phi)^{\alpha-1}}{i ! \bar{G}(x ; \phi)^{\alpha+1}} \exp \left\{-\left[\frac{G(x ; \phi)}{\bar{G}(x ; \phi)}\right]^{\alpha}\right\} \\
\times\left(1-\exp \left\{-\left[\frac{G(x ; \phi)}{\bar{G}(x ; \phi)}\right]^{\alpha}\right\}\right) .
\end{gathered}
$$

$$
f(x)=\sum_{i, j, k, m=0}^{\infty} \frac{(-1)^{j+k+m}}{i ! k !}\left(\begin{array}{l}
i \\
j
\end{array}\right)\left(\begin{array}{c}
-[\alpha(k+1)+1] \\
m
\end{array}\right) \frac{\theta^{i+1} \alpha(j+1)^{k}}{[\exp (\theta)-1]} g(x ; \phi) G(x ; \phi)^{\alpha(k+1)+m-1} .
$$

Then, the WGP density can be rewritten as

where $\pi_{\eta}(x)=\eta g(x ; \phi) G(x ; \phi)^{\eta-1}$ and

$$
f(x)=\sum_{k, m=0}^{\infty} \omega_{k, m} \quad \pi_{\alpha(k+1)+m}(x),
$$

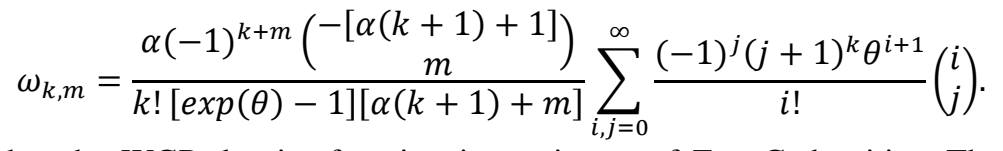

Equation (3) reveals that the WGP density function is a mixture of Exp-G densities. Thus, some mathematical properties of the new family can be derived from those properties of the Exp-G class. The CDF of the WGP family can also be expressed as a mixture of E-G densities. By integrating (3), we obtain the same mixture representation

$$
F(x)=\sum_{k, m=0}^{\infty} \omega_{k, m} \Pi_{\alpha(k+1)+m}(x),
$$

where $\Pi_{\eta}(x)$ is the CDF of the Exp-G family with power parameter $(\eta)$.

\section{Special WGP distributions}

The PDF (2) allows greater flexibility of its tails and can be widely applied in many applied areas of statistics. Now, we define and study two special models of the WGP family by taking the following baseline distributions: gamma (G), log-logistic (LL) and exponentiated exponential (EE) distributions. The PDF (2) will be most tractable when the CDF $G(x ; \phi)$ and the PDF $g(x ; \phi)$ have simple analytic expressions.

\subsection{The WG P distribution}

The $\mathrm{G}$ distribution with positive parameters $a$ and $b$ has PDF and CDF (for $x>0$ ) given by

$$
g(x)=\frac{1}{b^{a} \Gamma(a)} x^{a-1} \exp \left(-\frac{x}{b}\right) \quad \text { and } G(x)=\frac{1}{\Gamma(a)} \gamma\left(a, \frac{x}{b}\right)
$$

respectively, where $\gamma\left(a, \frac{x}{b}\right)=\int_{0}^{x / b} t^{a-1} e^{-t} d t$ is the incomplete gamma function. Then, the PDF of the WGP distribution reduces to

$$
\begin{gathered}
f(x)=\frac{\theta \alpha x^{a-1} \exp \left(-\frac{x}{b}\right) \Gamma(a)\left[\gamma\left(a, \frac{x}{b}\right)\right]^{\alpha-1}}{b^{a}[\exp (\theta)-1]\left[\Gamma(a)-\gamma\left(a, \frac{x}{b}\right)\right]^{\alpha+1}} \exp \left\{-\left[\frac{\gamma\left(a, \frac{x}{b}\right)}{\Gamma(a)-\gamma\left(a, \frac{x}{b}\right)}\right]^{\alpha}\right\} \\
\quad \times \exp \left(\theta-\theta \exp \left\{-\left[\frac{\gamma\left(a, \frac{x}{b}\right)}{\Gamma(a)-\gamma\left(a, \frac{x}{b}\right)}\right]^{\alpha}\right\}\right) .
\end{gathered}
$$

The plots in Figures 1 and 2 show some possible shapes of the density and hazard rate functions of the WGP distribution. 


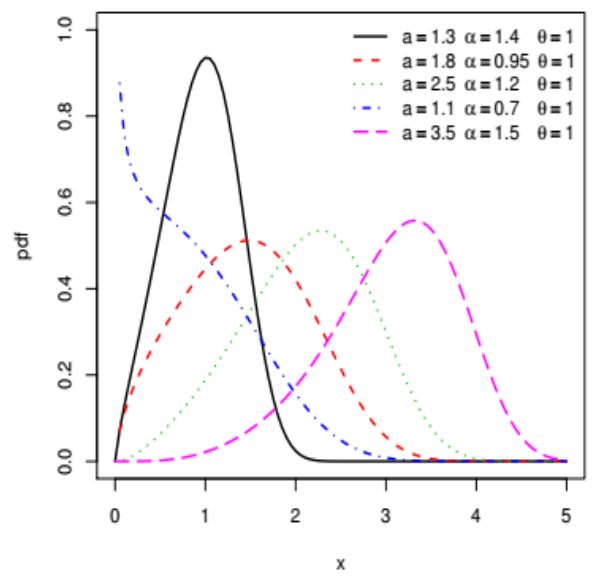

Figure 1: The WGP density plots (left panel).

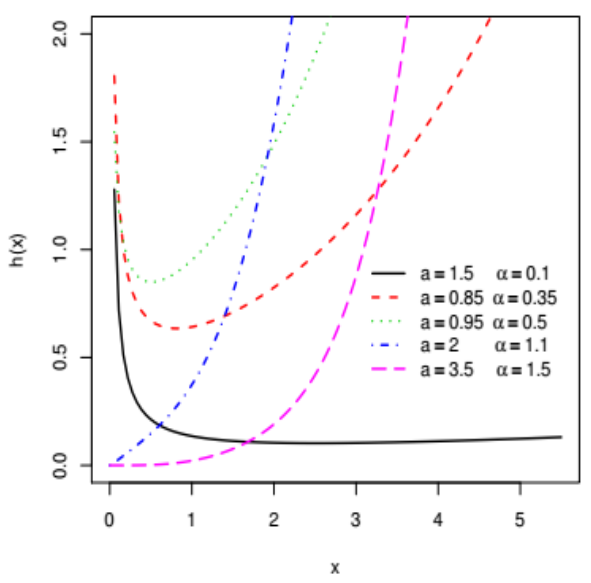

Figure 2: The WGP hrf plots (right panel). ]

\subsection{The WLLP distribution}

The LL distribution with positive parameters $c$ and $s$ has PDF and CDF given by $g(x)=\frac{c}{s}\left(\frac{x}{s}\right)^{c-1}\left[1+\left(\frac{x}{s}\right)^{c}\right]^{-2}$ (for $x>0$ ) and $G(x)=1-\left[1+\left(\frac{x}{s}\right)^{c}\right]^{-1}$, respectively. Then, the PDF of the WLLP distribution is given by

$$
\begin{gathered}
f(x)=\frac{\theta \alpha c x^{c-1}\left\{1-\left[1+\left(\frac{x}{s}\right)^{c}\right]^{-1}\right\}^{\alpha-1}}{s^{c}[\exp (\theta)-1]\left[1+\left(\frac{x}{s}\right)^{c}\right]^{-\alpha+1}} \exp \left[-\left(\frac{x}{s}\right)^{c \alpha}\right] \\
\quad \times \exp \left\{\theta-\theta \exp \left[-\left(\frac{x}{s}\right)^{c \alpha}\right]\right\} .
\end{gathered}
$$

Plots of the density and hazard rate functions of the WLLP distribution are displayed in Figures 3 and 4 for some parameter values.

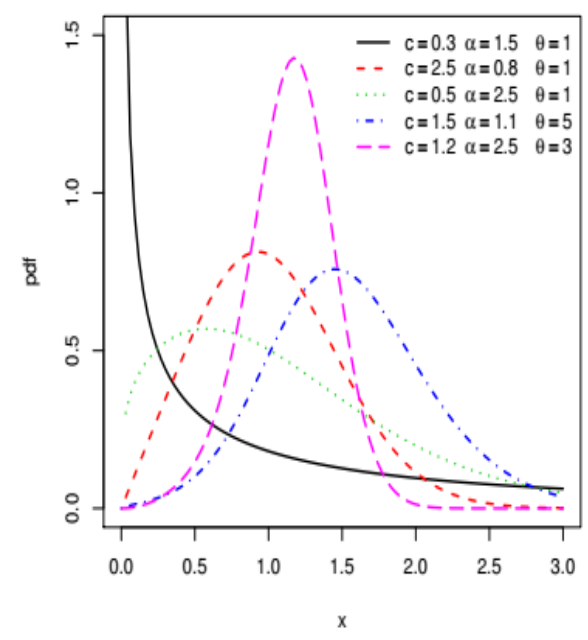

Figure 3: The WLLP density plots (left panel).

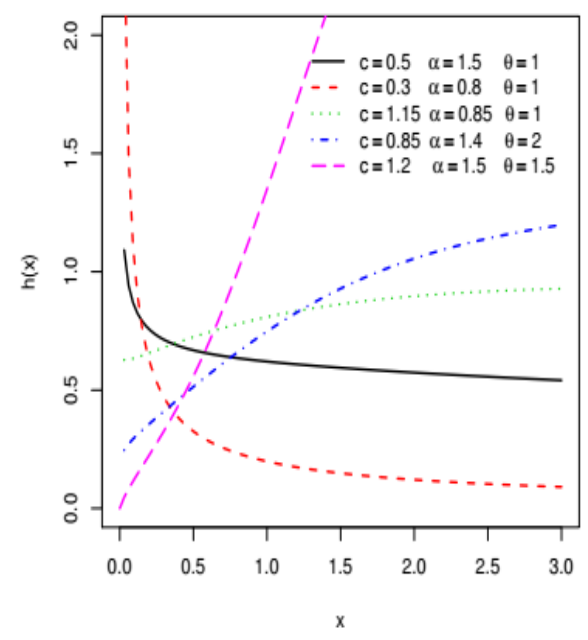

Figure 4: The WLLP hrf plots (right panel). 


\subsection{The WEEP distribution}

The EE distribution with scale parameter $\lambda>0$ and shape parameter $\beta>0$ has PDF and CDF given by $g(x)=$ $\beta \lambda \exp (-\lambda x)[1-\exp (-\lambda x)]^{\beta-1}$ (for $x>0$ ) and $G(x)=1[-\exp (-\lambda x)]^{\beta}$, respectively. Then, the WEEP density function reduces to

$$
\begin{aligned}
& f(x)=\frac{\theta \alpha \beta \lambda[1-\exp (-\lambda x)]^{\alpha \beta-1}}{\left\{1-[1-\exp (-\lambda x)]^{\beta}\right\}^{\alpha+1}} \exp \left(\frac{-[1-\exp (-\lambda x)]^{\alpha \beta}}{\left\{1-[1-\exp (-\lambda x)]^{\beta}\right\}^{\alpha}}\right) \\
& \times \frac{\exp (-\lambda x)}{[\exp (\theta)-1]} \exp \left[\theta-\theta \exp \left(\frac{-[1-\exp (-\lambda x)]^{\alpha \beta}}{\left\{1-[1-\exp (-\lambda x)]^{\beta}\right\}^{\alpha}}\right)\right] .
\end{aligned}
$$

Figures 5 and 6 display some possible shapes of the density and hazard rate functions of this distribution.

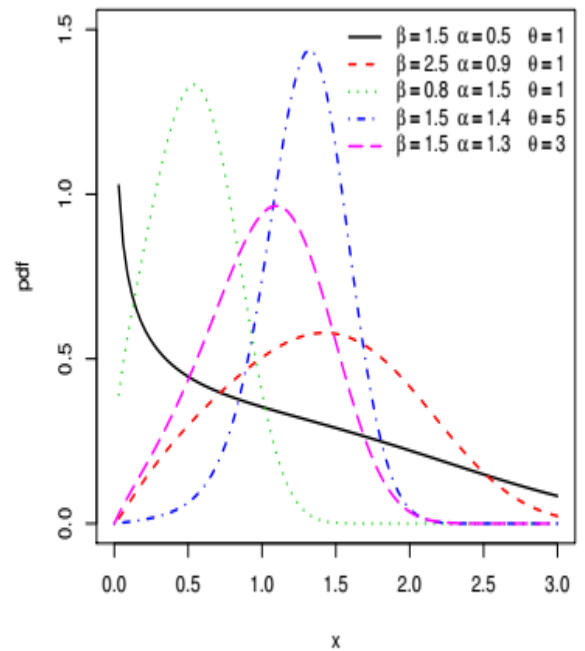

Figure 5: The WEEP density plots (left panel).

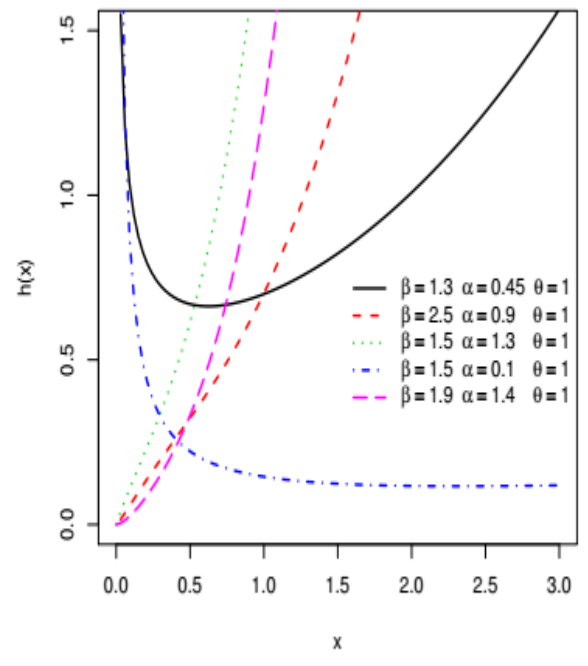

Figure 6: The WEEP hrf plots (right panel).

\section{Mathematical properties}

In this section, we derive some general mathematical properties of the new family. Established explicit expressions to calculate statistical measures can be more efficient than computing them directly by numerical integration.

\subsection{Quantile and generating functions}

The quantile function (qf) of $X$, where $X \sim \operatorname{WGP}(\theta, \alpha, \phi)$, is obtained by inverting (1) to optain $Q(u)=F^{-1}$, $0 \leq u \leq 1$.

Simulating the WGP random variable is straightforward. If $U$ is a uniform variate on the unit interval $(0,1)$, then the random variable $X=Q(U)$ follows (2).

For simulating from WGP if $u \sim u(0,1)$, then solution of nonlinear equation

$$
x_{u}=G^{-1}\left[\frac{\left(-\log \left\{1-\frac{1}{\theta} \log [1+u(\exp (\theta)-1)]\right\}\right)^{\frac{1}{\alpha}}}{1+\left(-\log \left\{1-\frac{1}{\theta} \log [1+u(\exp (\theta)-1)]\right\}\right)^{\frac{1}{\alpha}}}\right] .
$$

Here, we provide two formulae for the $\operatorname{mgf} M_{X}(t)=E\left(e^{t X}\right)$ of $X$. Clearly, the first one can be derived from equation (3) as

$$
M_{X}(t)=\sum_{k, m=0}^{\infty} \omega_{k, m} M_{\alpha(k+1)+m}(t)
$$

where $M_{k}(t)$ is the mgf of $Y_{k}$. Hence, $M_{X}(t)$ can be determined from the exp-G generating function. A second formula for $M_{X}(t)$ follows from (3) as 


$$
M_{X}(t)=\sum_{k, m=0}^{\infty} \omega_{k, m} \tau(t, \alpha[k+1]+m-1),
$$

where $\tau(t, k)=\int_{0}^{1} \exp \left[t Q_{G}(u)\right] u^{k} d u$ and $Q_{G}(u)$ is the qf corresponding to $G(x ; \phi)$, i.e., $Q_{G}(u)=$ $G^{-1}(u ; \phi)$.

\subsection{Ordinary and incomplete moments}

The $r$ th moment of $X$, say $\mu_{r}^{\prime}$, follows from (3) as

$$
\mu_{r}^{\prime}=E\left(X^{r}\right)=\sum_{k, m=0}^{\infty} \omega_{k, m} E\left(Y_{\alpha(k+1)+m}^{r}\right) .
$$

Henceforth, $Y_{\gamma}$ denotes the Exp-G distribution with power parameter $\gamma$.

The variance, skewness, and kurtosis measures can now be calculated using the well-known relations. The $n$th central moment of $X$, say $M_{n}$, is given by

$$
\begin{aligned}
& M_{n}=E\left(X-\mu_{1}^{\prime}\right)^{n}=\sum_{r=0}^{n}\left(\begin{array}{l}
n \\
r
\end{array}\right)\left(-\mu_{1}^{\prime}\right)^{n-r} E\left(X^{r}\right) \\
& =\sum_{r=0}^{n} \sum_{k, m=0}^{\infty} \omega_{k, m}\left(\begin{array}{l}
n \\
r
\end{array}\right)\left(\mu_{r}^{\prime}\right)^{n-r} E\left(Y_{\alpha(k+1)+m}^{r}\right) .
\end{aligned}
$$

The cumulants $\left(\kappa_{n}\right)$ of $X$ follow recursively from

$$
\kappa_{n}=\mu_{n}^{\prime}-\sum_{r=0}^{n-1}\left(\begin{array}{l}
n-1 \\
r-1
\end{array}\right) \kappa_{r} \mu_{n-r}^{\prime},
$$

where $\kappa_{1}=\mu_{1}^{\prime}, \kappa_{2}=\mu_{2}^{\prime}-\mu_{1}^{\prime 2}, \kappa_{3}=\mu_{3}^{\prime}-3 \mu_{2}^{\prime} \mu_{1}^{\prime}+\mu_{1}^{\prime 3}$, etc.

The main applications of the first incomplete moment refer to the mean deviations and the Bonferroni and Lorenz curves. These curves are very useful in economics, reliability, demography, insurance and medicine. The $s$ th incomplete moment, say $\phi_{s}(t)$, of $X$ can be expressed from (3) as

$$
\phi_{S}(t)=\int_{-\infty}^{t} x^{s} f(x) d x=\sum_{k, m=0}^{\infty} \omega_{k, m} \int_{-\infty}^{t} x^{s} \pi_{\alpha(k+1)+m}(x) d x
$$

\subsection{Mean Deviations}

The mean deviations about the mean $\left[\alpha_{1}=E\left(\left|X-\mu_{1}^{\prime}\right|\right)\right]$ and about the median $\left[\alpha_{2}=E(|X-M|)\right]$ of $X$ are given by $\alpha_{1}=2 \mu_{1}^{\prime} F\left(\mu_{1}^{\prime}\right)-2 \phi_{1}\left(\mu_{1}^{\prime}\right)$ and $\alpha_{2}=\mu_{1}^{\prime}-2 \phi_{1}(M)$, respectively, where $\mu_{1}^{\prime}=E(X), M=\operatorname{Median}(X)=$ $Q(0.5)$ is the median, $F\left(\mu_{1}^{\prime}\right)$ is easily calculated from (1) and $\phi_{1}(t)$ is the first incomplete moment given by (6) with $s=1$. Now, we provide two ways to determine $\alpha_{1}$ and $\alpha_{2}$.

First, a general Equation for $\phi_{1}(t)$ can be derived from (6) as

$$
\phi_{1}(t)=\sum_{k, m=0}^{\infty} \omega_{k, m} V_{\alpha(k+1)+m}(x),
$$

where $V_{k}(x)=\int_{-\infty}^{t} x \pi_{k}(x) d x$ is the first incomplete moment of the Exp-G distribution. A second general formula for $\phi_{1}(t)$ is given by

$$
\phi_{1}(t)=\sum_{k, m=0}^{\infty} \omega_{k, m} v_{\alpha(k+1)+m-1}(t),
$$

where $v_{k-1}(t)=k \int_{0}^{G(t)} Q_{G}(u) u^{k-1} d u$ can be computed numerically.

These equations for $\phi_{1}(t)$ can be applied to construct Bonferroni and Lorenz curves defined for a given probability $\pi$ by $B(\pi)=\phi_{1}(q) /\left(\pi \mu_{1}^{\prime}\right)$ and $L(\pi)=\phi_{1}(q) / \mu_{1}^{\prime}$, respectively, where $\mu_{1}^{\prime}=E(X)$ and $q=Q(\pi)$ is the qf of $X$ at $\pi$. 
Table 1: Mean, variance, skewness and kurtosis for the WEEP distribution

\begin{tabular}{|c|c|c|c|c|c|c|}
\hline$\theta$ & $\alpha$ & $\beta$ & Mean & Variance & Skewness & Kurtosis \\
\hline \multirow[t]{12}{*}{0.5} & 0.5 & 0.5 & 0.01598 & 0.00464 & 8.34499 & 104.5005 \\
\hline & & 1.5 & 0.10004 & 0.05089 & 3.38828 & 17.8778 \\
\hline & & 2 & 0.14287 & 0.08365 & 2.79435 & 12.58904 \\
\hline & & 5 & 0.34026 & 0.30518 & 1.66057 & 5.29040 \\
\hline & 1.5 & 0.5 & 0.00927 & 0.00175 & 6.65653 & 6.65652 \\
\hline & & 1.5 & 0.053683 & 0.03151 & 3.76445 & 17.89543 \\
\hline & & 2 & 0.07273 & 0.05369 & 3.45308 & 14.90687 \\
\hline & & 5 & 0.14842 & 0.19721 & 2.92195 & 10.38314 \\
\hline & 2 & 0.5 & 0.00572 & 0.00104 & 7.71279 & 74.99725 \\
\hline & & 1.5 & 0.03177 & 0.02002 & 4.93748 & 28.53828 \\
\hline & & 2 & 0.04252 & 0.03401 & 4.64573 & 24.90873 \\
\hline & & 5 & 0.08420 & 0.12229 & 4.15565 & 19.28276 \\
\hline \multirow[t]{16}{*}{1.5} & 0.5 & 0.5 & 0.01627 & 0.00541 & 8.34159 & 101.6934 \\
\hline & & 1.5 & 0.08903 & 0.05313 & 3.70740 & 20.24034 \\
\hline & & 2 & 0.12384 & 0.08556 & 3.14089 & 14.75641 \\
\hline & & 5 & 0.27772 & 0.29740 & 2.06815 & 6.86562 \\
\hline & 1.5 & 0.5 & 0.00822 & 0.00183 & 7.28082 & 67.63469 \\
\hline & & 1.5 & 0.04222 & 0.02818 & 4.51647 & 24.56415 \\
\hline & & 2 & 0.05619 & 0.04668 & 4.20113 & 21.01491 \\
\hline & & 5 & 0.11058 & 0.16112 & 3.64668 & 15.36836 \\
\hline & 2 & 0.5 & 0.00484 & 0.00103 & 8.69822 & 91.90487 \\
\hline & & 1.5 & 0.02419 & 0.01693 & 5.96136 & 40.4247 \\
\hline & & 2 & 0.03189 & 0.02802 & 5.65369 & 35.90259 \\
\hline & & 5 & 0.06129 & 0.09533 & 5.11985 & 28.57023 \\
\hline & 5 & 0.5 & 0.00012 & 2.56279 & 47.00557 & 2423.183 \\
\hline & & 1.5 & 0.00056 & 0.00044 & 39.3412 & 1614.199 \\
\hline & & 2 & 0.00072 & 0.00071 & 38.53685 & 1536.394 \\
\hline & & 5 & 0.00131 & 0.00229 & 37.18356 & 1407.508 \\
\hline \multirow[t]{8}{*}{2} & 0.5 & 0.5 & 0.01609 & 0.00571 & 8.42407 & 102.3361 \\
\hline & & 1.5 & 0.08265 & 0.05320 & 3.91368 & 21.94791 \\
\hline & & 2 & 0.11351 & 0.08477 & 3.35794 & 16.28804 \\
\hline & & 5 & 0.24729 & 0.28686 & 2.30769 & 7.97881 \\
\hline & 1.5 & 0.5 & 0.00769 & 0.00185 & 7.62109 & 72.694 \\
\hline & & 1.5 & 0.03722 & 0.02642 & 4.93981 & 28.7914 \\
\hline & & 2 & 0.04908 & 0.04316 & 4.62583 & 24.96535 \\
\hline & & 5 & 0.09477 & 0.14434 & 4.06486 & 18.7226 \\
\hline
\end{tabular}


Table 1: Mean, variance, skewness and kurtosis for the WEEP distribution (Continuing)

\begin{tabular}{|c|c|c|c|c|c|c|}
\hline$\theta$ & $\alpha$ & $\beta$ & Mean & Variance & Skewness & Kurtosis \\
\hline \multirow{24}{*}{5} & \multirow[t]{4}{*}{2} & 0.5 & 0.00444 & 0.00102 & 9.22235 & 101.5581 \\
\hline & & 1.5 & 0.02102 & 0.01549 & 6.54351 & 48.06931 \\
\hline & & 2 & 0.02749 & 0.02531 & 6.23262 & 43.10474 \\
\hline & & 5 & 0.05197 & 0.08367 & 5.68358 & 34.85865 \\
\hline & \multirow[t]{4}{*}{5} & 0.5 & 0.00011 & 0.00002 & 51.59404 & 2895.111 \\
\hline & & 1.5 & 0.00047 & 0.00038 & 43.70736 & 1988.029 \\
\hline & & 2 & 0.00059 & 0.00061 & 42.85088 & 1896.793 \\
\hline & & 5 & 0.00108 & 0.00191 & 41.39155 & 1743.229 \\
\hline & \multirow[t]{4}{*}{0.5} & 0.5 & 0.01249 & 0.00626 & 9.84363 & 129.5283 \\
\hline & & 1.5 & 0.04625 & 0.04359 & 5.75658 & 41.74523 \\
\hline & & 2 & 0.05952 & 0.06515 & 5.23424 & 34.06376 \\
\hline & & 5 & 0.11131 & 0.18621 & 4.24021 & 21.55607 \\
\hline & \multirow[t]{4}{*}{1.5} & 0.5 & 0.00512 & 0.00179 & 9.84951 & 111.4646 \\
\hline & & 1.5 & 0.01827 & 0.01763 & 7.82813 & 66.54218 \\
\hline & & 2 & 0.02289 & 0.02681 & 7.577204 & 61.81638 \\
\hline & & 5 & 0.03965 & 0.07564 & 7.100170 & 53.25236 \\
\hline & \multirow[t]{4}{*}{2} & 0.5 & 0.00274 & 0.00089 & 12.43983 & 171.2925 \\
\hline & & 1.5 & 0.00982 & 0.00947 & 10.48454 & 116.2765 \\
\hline & & 2 & 0.01228 & 0.01446 & 10.23989 & 110.1829 \\
\hline & & 5 & 0.02111 & 0.04092 & 9.77559 & 98.95934 \\
\hline & \multirow[t]{4}{*}{5} & 0.5 & 0.00005 & 0.00001 & 78.65482 & 6389.314 \\
\hline & & 1.5 & 0.00018 & 0.00017 & 74.58790 & 5670.93 \\
\hline & & 2 & 0.00023 & 0.00027 & 73.88042 & 5545.666 \\
\hline & & 5 & 0.00038 & 0.00076 & 72.56972 & 5315.87 \\
\hline
\end{tabular}

\subsection{Entropies}

The Rényi entropy of a random variable $X$ represents a measure of variation of the uncertainty. The Rényi entropy is defined by

Then, we can write

$$
I_{\delta}(X)=(1-\delta)^{-1} \log \left(\int_{-\infty}^{\infty} f(x)^{\delta} d x\right), \delta>0 \text { and } \delta \neq 1
$$

$$
\begin{aligned}
& f(x)^{\delta}=\left(\frac{\theta \alpha}{e^{\theta}-1}\right)^{\delta} \exp \left\{-\delta\left[\frac{G(x)}{\bar{G}(x)}\right]^{\alpha}\right\} \exp \left(\theta \delta-\theta \delta \exp \left\{-\left[\frac{G(x)}{\bar{G}(x)}\right]^{\alpha}\right\}\right) \\
& =\sum_{i, j=0}^{\infty} \frac{(-1)^{j} \theta^{\delta+i} \alpha^{\delta} \delta^{i} g(x)^{\delta} G(x)^{\delta \alpha-\delta}}{i !\left(e^{\theta}-1\right)^{\delta} \bar{G}(x)^{\delta \alpha+\delta}}\left(\begin{array}{l}
i \\
j
\end{array}\right) \exp \left\{-(j+\delta)\left[\frac{G(x)}{\bar{G}(x)}\right]^{\alpha}\right\} .
\end{aligned}
$$

After some algebra, we have

$$
f(x)^{\delta}=\sum_{k, m=0}^{\infty} \tau_{k, m} g(x)^{\delta} G(x)^{\alpha k+\delta(\alpha-1)+m}
$$

where

$$
\tau_{k, m}=\frac{(-1)^{k+m} \alpha^{\delta}}{k !\left(e^{\theta}-1\right)^{\delta}}\left(\begin{array}{c}
-\alpha k-\delta(\alpha+1) \\
m
\end{array}\right) \sum_{i, j=0}^{\infty} \frac{(-1)^{j} \delta^{i}(j+\delta)^{k} \theta^{\delta+i}}{i !}\left(\begin{array}{l}
i \\
j
\end{array}\right) .
$$

Then, the Rényi entropy can be expressed as

$$
I_{\delta}(X)=(1-\delta)^{-1} \log \left[\sum_{k, m=0}^{\infty} \tau_{k, m} \int_{-\infty}^{\infty} g(x)^{\delta} G(x ; \phi)^{\alpha k+\delta(\alpha-1)+m} d x\right] .
$$

The $\delta$-entropy, say $H_{\delta}(X)$, can be obtained as

$$
H_{\delta}(X)=\frac{1}{\delta-1} \log \left\{1-\left[\sum_{k, m=0}^{\infty} \tau_{k, m} \int_{-\infty}^{\infty} g(x)^{\delta} G(x ; \phi)^{\alpha k+\delta(\alpha-1)+m} d x\right]\right\} .
$$


The Shannon entropy of a random variable $X$, say $S I$, is defined by

$$
S I=E\{-[\log f(X)]\} \text {. }
$$

The Shannon entropy is a special case of the Rényi entropy when $\delta \uparrow 1$ and it follows by taking the limit of $I_{\delta}(X)$ as $\delta$ tends to 1 .

\subsection{Order statistics}

Order statistics make their appearance in many areas of statistical theory and practice. Let $X_{1}, \ldots, X_{n}$ be a random sample from the WGP family of distributions. The PDF of $i$ th order statistic, say $X_{i}: n$, can be written as

$$
f_{i}:{ }_{n}(x)=\frac{f(x)}{B(i, n-i+1)} \sum_{j=0}^{n-i}(-1)^{j}\left(\begin{array}{c}
n-i \\
j
\end{array}\right) F(x)^{j+i-1} \text {. }
$$

Using (1), (2) and (7) we get

$$
f(x) F(x)^{j+i-1}=\sum_{k, m=0}^{\infty} t_{k, m} \quad \pi_{\alpha(k+1)+m}(x),
$$

where $\pi_{k}(x)$ is the Exp-G density with power parameter $\eta$ and

$$
\begin{gathered}
t_{k, m}=\frac{\alpha(-1)^{k+m}}{k !\left(e^{\theta}-1\right)^{j+i}} \sum_{l=0}^{j+i-1} \sum_{h, w=0}^{\infty} \frac{(-1)^{l+w}}{h !} \theta^{h+1}(j+i-l)^{h}(w+1)^{k} \\
\times\left(\begin{array}{c}
r \\
l
\end{array}\right)\left(\begin{array}{c}
h \\
w
\end{array}\right)\left(\begin{array}{c}
-[\alpha+1)+1] \\
m
\end{array}\right) .
\end{gathered}
$$

Substituting (8) in equation (7), the PDF of $X_{i}: n_{n}$ can be expressed as

$$
f_{i}:{ }_{n}(x)=\sum_{k, m=0}^{\infty} \sum_{j=0}^{n-i} \frac{(-1)^{j} t_{k, m}}{B(i, n-i+1)}\left(\begin{array}{c}
n-i \\
j
\end{array}\right) \pi_{\alpha(k+1)+m}(x) .
$$

Then, the density function of the WGP order statistics is a mixture of Exp-G densities. Based on the last Equation, we note that the properties of $X_{i}: n$ follow from those properties of $Y_{\alpha(1+k)+m}$. For example, the moments of $X_{i}: n$ can be expressed as

$$
E\left(X_{i}^{q}: n\right)=\sum_{k, m=0}^{\infty} \sum_{j=0}^{n-i} \frac{(-1)^{j} t_{k, m}}{B(i, n-i+1)}\left(\begin{array}{c}
n-i \\
j
\end{array}\right) E\left(Y_{\alpha(k+1)+m}^{q}\right)
$$

\subsection{Stress-strength model}

Stress-strength model is the most widely approach used for reliability estimation. This model is used in many applications of physics and engineering such as strength failure and system collapse. In stress-strength modeling, say $R\left(X_{1}, X_{2} \mid X_{1}>X_{2}\right)=\operatorname{Pr}\left(\mid X_{1}>X_{2}\right)$, is a measure of reliability of the system when it is subjected to random stress $X_{2}$ and has strength $X_{1}$.

The system fails if and only if the applied stress is greater than its strength and the component will function satisfactorily whenever $X_{1}>X_{2} \cdot R\left(X_{1}, X_{2} \mid X_{1}>X_{2}\right)$ can be considered as a measure of system performance and naturally arise in electrical and electronic systems. Further, the reliability of the system is the probability that the system is strong enough to overcome the stress imposed on it.

Let $X_{1}$ and $X_{2}$ be two independent random variables have WGP $\left(\theta_{1}, \alpha_{1}, \phi\right)$ and WGP $\left(\theta_{1}, \alpha_{1}, \phi\right)$ distributions .The PDF of $X_{1}$ and the CDF of $X_{2}$ can be written from equations (1) and (2), respectively as

and

$$
\begin{aligned}
& f_{1}\left(\theta_{1}, \alpha_{1}, \phi\right)=\sum_{k, m=0}^{\infty} \frac{\alpha_{1}(-1)^{k+m}}{k !\left(e^{\theta_{1}}-1\right)}\left(\begin{array}{c}
-\alpha_{1}(k+1)-1 \\
m
\end{array}\right) \\
& \times \sum_{i, j=0}^{\infty}\left(\begin{array}{l}
i \\
j
\end{array}\right) g(x ; \phi) G(x ; \phi)^{\alpha_{1}(k+1)+m-1}
\end{aligned}
$$

$$
F_{2}\left(\theta_{2}, \alpha_{2}, \phi\right)=\sum_{l, w=0}^{\infty} \frac{\alpha_{2}(-1)^{l+w}}{l !\left(e^{\theta_{2}}-1\right)\left[\alpha_{2}(l+1)+w\right]}\left(\begin{array}{c}
-\alpha_{2}(l+1)-1 \\
w
\end{array}\right)
$$




$$
\times \sum_{h, d=0}^{\infty} \frac{(-1)^{d} \theta_{2}{ }^{h+1}}{h !(d+1)^{-l}}\left(\begin{array}{l}
h \\
d
\end{array}\right) G(x ; \phi)^{\alpha_{2}(l+1)+w} .
$$

Then, $R\left(X_{1}, X_{2} \mid X_{1}>X_{2}\right)$ is given by

where

$$
\begin{aligned}
& R\left(X_{1}, X_{2} \mid X_{1}>X_{2}\right)=\int_{0}^{\infty} f_{1}\left(\theta_{1}, \alpha_{1}, \phi\right) F_{2}\left(\theta_{2}, \alpha_{2}, \phi\right) d x \\
& =\sum_{k, m, l, w=0}^{\infty} d_{k, m, l, w},
\end{aligned}
$$

$$
\begin{aligned}
& d_{k, m, l, w}=\frac{\alpha_{1} \alpha_{2}(-1)^{k+m+l+w}}{k ! l !\left(e^{\theta_{1}}-1\right)\left(e^{\theta_{2}}-1\right)\left[\alpha_{2}(l+1)+w\right]} \\
& \times\left(\begin{array}{c}
-\alpha_{2}(l+1)-1 \\
w
\end{array}\right)\left(\begin{array}{c}
-\alpha_{1}(k+1)-1 \\
m
\end{array}\right) \\
& \times \sum_{i, j, h, d=0}^{\infty} \frac{\theta_{1}{ }^{i+1} \theta_{2}{ }^{h+1}(-1)^{j+d}(j+1)^{k}(d+1)^{l}}{i ! h !\left[\alpha_{1}(k+1)+\alpha_{2}(l+1)+m+w\right]}\left(\begin{array}{l}
i \\
j
\end{array}\right)\left(\begin{array}{l}
h \\
d
\end{array}\right) \text {. }
\end{aligned}
$$

\section{Estimation}

Several approaches for parameter estimation were proposed in the literature but the maximum likelihood method is the most commonly employed. Here, we consider the estimation of the unknown parameters of the new family from complete samples only by maximum likelihood. Let $x_{1}, \ldots, x_{n}$ be a random sample from the WGP family with parameters $\alpha, \theta$ and $\phi$. Let $\Theta$ be the $p \times 1$ parameter vector. To obtain the MLE of $\Theta$, the log-likelihood function, $\ell=\ell(\Theta)$, is given by

$$
\begin{aligned}
& \ell=n \log \theta+n \log \alpha-n \log \left(e^{\theta}-1\right)+(\alpha-1) \sum_{i=0}^{n} \log G\left(x_{i} ; \phi\right) \\
& +\sum_{i=0}^{n} \log g\left(x_{i} ; \phi\right)-(\alpha+1) \sum_{i=0}^{n} \log \bar{G}\left(x_{i} ; \phi\right)-\sum_{i=0}^{n} p_{i}+\theta \sum_{i=0}^{n} q_{i}
\end{aligned}
$$

where $p_{i}=\left[G\left(x_{i} ; \phi\right) / \bar{G}\left(x_{i} ; \phi\right)\right]^{\alpha}$ and $q_{i}=1-\exp \left(-p_{i}\right)$.

The components of the score vector are

$$
\begin{gathered}
U_{\theta}=\frac{n}{\theta}-\frac{n e^{\theta}}{\left(e^{\theta}-1\right)}+\sum_{i=0}^{n} q_{i} \\
U_{\alpha}=\frac{n}{\alpha}+\sum_{i=0}^{n} \log G\left(x_{i} ; \phi\right)-\sum_{i=0}^{n} \log \bar{G}(x ; \phi) \\
-\sum_{i=0}^{n} p_{i} \log \left[\frac{G\left(x_{i} ; \phi\right)}{\bar{G}\left(x_{i} ; \phi\right)}\right]+\theta \sum_{i=0}^{n} p_{i} e^{-p_{i}} \log \left[\frac{G\left(x_{i} ; \phi\right)}{\bar{G}\left(x_{i} ; \phi\right)}\right]
\end{gathered}
$$

and

$$
\begin{aligned}
& U_{\phi_{k}}=\sum_{i=0}^{n} \frac{g^{\prime}\left(x_{i} ; \phi\right)}{g\left(x_{i} ; \phi\right)}+(\alpha-1) \sum_{i=0}^{n} \frac{G^{\prime}\left(x_{i} ; \phi\right)}{G\left(x_{i} ; \phi\right)}-\alpha \sum_{i=0}^{n} \frac{G^{\prime}\left(x_{i} ; \phi\right)}{\bar{G}\left(x_{i} ; \phi\right)^{2}}\left[\frac{G\left(x_{i} ; \phi\right)}{\bar{G}\left(x_{i} ; \phi\right)}\right]^{\alpha-1} \\
& +(\alpha+1) \sum_{i=0}^{n} \frac{G^{\prime}\left(x_{i} ; \phi\right)}{\bar{G}(x ; \phi)}+\alpha \theta \sum_{i=0}^{n} e^{-p_{i}} \frac{G^{\prime}\left(x_{i} ; \phi\right)}{\bar{G}\left(x_{i} ; \phi\right)^{2}}\left[\frac{G\left(x_{i} ; \phi\right)}{\bar{G}\left(x_{i} ; \phi\right)}\right]^{\alpha-1},
\end{aligned}
$$

where $g^{\prime}\left(x_{i} ; \phi\right)=\partial g\left(x_{i} ; \phi\right) / \partial \phi_{k} \quad$ and $\quad G^{\prime}\left(x_{i} ; \phi\right)=\partial G\left(x_{i} ; \phi\right) / \partial \phi_{k}$.

Setting the nonlinear system of equations $U_{\theta}=U_{\alpha}=0$ and $U_{\phi_{k}}=0$ and solving them simultaneously yields the MLEs. For doing this, it is usually more convenient to adopt nonlinear optimization methods such as the quasi-Newton algorithm to maximize $\ell$ numerically. For interval estimation of the parameters, we obtain the $p \times p$ observed information matrix $J(\boldsymbol{\Theta})=\left\{\frac{\partial^{2} \ell}{\partial r \partial s}\right\}$ (for $\left.r, s=\theta, \alpha, \phi\right)$, whose elements can be computed numerically. Under standard 
regularity conditions when $n \rightarrow \infty$, the distribution of $\widehat{\boldsymbol{\Theta}}$ can be approximated by a multivariate normal distribution to obtain confidence intervals for the parameters. Here, $\boldsymbol{J}(\widehat{\boldsymbol{\Theta}})$, is the total observed information matrix evaluated at $\widehat{\Theta}$ . The elements of $J(\Theta)$ are given in the Appendix A.

\section{Simulation study}

In this section, we evaluate the performance of the MLEs by using Monte Carlo simulation for different sample sizes and different parameter values. We choose PWEE model for this purpose. The simulation study is repeated 10,000 times each with sample sizes $n=25,50,75,100,200,400$ and parameter combinations

I: $\beta=0.5, \alpha=0.5, \lambda=1$, and II: $\beta=0.5, \alpha=1.5, \lambda=2$.

Table 2 presents the average bias (Bias), Mean Square Error (MSE), Coverage Probability (CP), average lower bound (LB) and average upper bound (UB) values of the parameters $\beta, \alpha$ and $\lambda$ for different sample sizes. From the results, we can verify that the Bias and MSEs decreases as the sample size $n$ increases. The CP of the confidence intervals are quite close to the nominal level of $95 \%$. Therefore, the MLEs and their asymptotic results can be used for estimating and constructing confidence intervals even for reasonably small sample sizes.

Table 2: Monte Carlo simulation results: Bias, MSE, CP, LB and UB.

\begin{tabular}{ccccccc|cccccc}
\hline \multicolumn{1}{c}{$n$} & Bias & MSE & CP & LB & UB & $n$ & Bias & MSE & CP & LB & UB \\
\hline \multicolumn{1}{c}{$\beta$} & & I & & & & & & II & & & \\
\hline$\beta$ & 25 & 0.821 & 1.491 & 0.94 & 0.133 & 2.272 & 25 & 0.525 & 1.164 & 0.93 & 0.138 & 2.989 \\
& 50 & 0.553 & 0.165 & 0.94 & 0.738 & 1.838 & 50 & 1.169 & 1.006 & 0.98 & 0.761 & 2.100 \\
& 75 & 0.414 & 0.093 & 0.94 & 0.407 & 1.214 & 75 & 0.817 & 0.592 & 0.98 & 0.228 & 1.561 \\
& 100 & 0.320 & 0.047 & 0.95 & 0.254 & 1.857 & 100 & 0.598 & 0.046 & 0.90 & 0.542 & 1.727 \\
& 200 & 0.182 & 0.017 & 0.95 & 0.139 & 1.293 & 200 & 0.264 & 0.029 & 0.92 & 0.300 & 1.463 \\
& 400 & 0.088 & 0.005 & 0.93 & 0.241 & 0.943 & 400 & 0.098 & 0.009 & 0.92 & 0.482 & 0.765 \\
$\alpha$ & 25 & 0.009 & 0.252 & 0.79 & 0.519 & 1.534 & 25 & 0.094 & 0.400 & 0.92 & 0.651 & 1.838 \\
& 50 & -0.017 & 0.152 & 0.78 & 0.218 & 1.176 & 50 & 0.175 & 0.526 & 0.94 & 0.492 & 1.830 \\
& 75 & -0.029 & 0.098 & 0.79 & 0.112 & 1.019 & 75 & 0.147 & 0.404 & 0.94 & 0.286 & 1.540 \\
& 100 & -0.032 & 0.073 & 0.82 & 0.088 & 0.949 & 100 & 0.146 & 0.098 & 0.94 & 0.248 & 1.458 \\
& 200 & -0.034 & 0.032 & 0.84 & 0.149 & 0.797 & 200 & 0.092 & 0.055 & 0.91 & 0.168 & 1.109 \\
400 & -0.023 & 0.006 & 0.86 & 0.248 & 0.716 & 400 & 0.070 & 0.005 & 0.91 & 0.230 & 0.922 \\
$\lambda$ & 25 & 1.703 & 1.394 & 0.92 & 0.333 & 4.727 & 25 & 0.640 & 1.973 & 0.93 & 0.069 & 1.292 \\
& 50 & 1.222 & 0.256 & 0.92 & 1.719 & 2.142 & 50 & 0.316 & 0.964 & 0.90 & 0.574 & 1.057 \\
75 & 0.942 & 0.103 & 0.93 & 0.178 & 1.913 & 75 & 0.251 & 0.698 & 0.93 & 0.407 & 2.666 \\
100 & 0.764 & 0.092 & 0.94 & 0.774 & 1.249 & 100 & 0.179 & 0.511 & 0.89 & 0.376 & 2.402 \\
200 & 0.448 & 0.063 & 0.93 & 0.319 & 1.004 & 200 & 0.063 & 0.249 & 0.91 & 0.362 & 1.942 \\
400 & 0.233 & 0.012 & 0.92 & 0.322 & 1.009 & 400 & 0.013 & 0.040 & 0.92 & 0.426 & 1.658 \\
\hline
\end{tabular}

\section{Applications}

In this section, we consider three applications to three real data sets to illustrate the flexibility of the new family of distribution. We also analyzed the hazard rates of these three data sets. In order to identify the shapes of data, we consider the graphical method based on total time on test (TTT) transformed, introduced by Barlow and Campo (1975). The empirical illustration of TTT transform is given by Aarset (1987).

The first data set presents increasing-shaped (unimodal) hazard function while the second and third data sets present upside-down bathtub shaped hazard function. From Figure 3(a), the TTT plot for the data set 1 shows that hazard function $\tau(x)$ is concave giving an indication of increasing shape, while in Figures 4(c) and 5(e), TTT-plot for the data sets 2 and 3 show that the hazard rate function is first concave and then convex, giving an indication of upside-down bathtub shape. Hence, the WGP family could be in principle an appropriate model for fitting these data sets. 
The Figures 8, 10 and 12, we consider kernel density estimation (a non- parametric approach) with Gaussian Filter. Let $X_{1}, X_{2}, \ldots, X_{n}$ be an independently identically distributed (IID) random vector of variables which follows an unknown distribution $f$. The kernel density estimator is given by

$$
\hat{f}_{h}(x)=\frac{1}{n} \sum_{i=1}^{n} K_{h}\left(x-x_{i}\right)=\frac{1}{n h} \sum_{i=1}^{n} K\left[\frac{x-x_{j}}{h}\right]
$$

where $K($.$) is the kernel function usually symmetric and \int_{-\infty}^{\infty} K(x) d x=1$, and $h>0$ is a smoothing parameter, also known as bandwidth.

The MLEs are calculated and the goodness-of-fit statistics including the log-likelihood function evaluated at the MLEs, Akaike information criterion (AIC), Kolmogorov-Smirnov (K-S) and its P-value are determined to compare the fitted models. The required computations are carried out in the R-language.

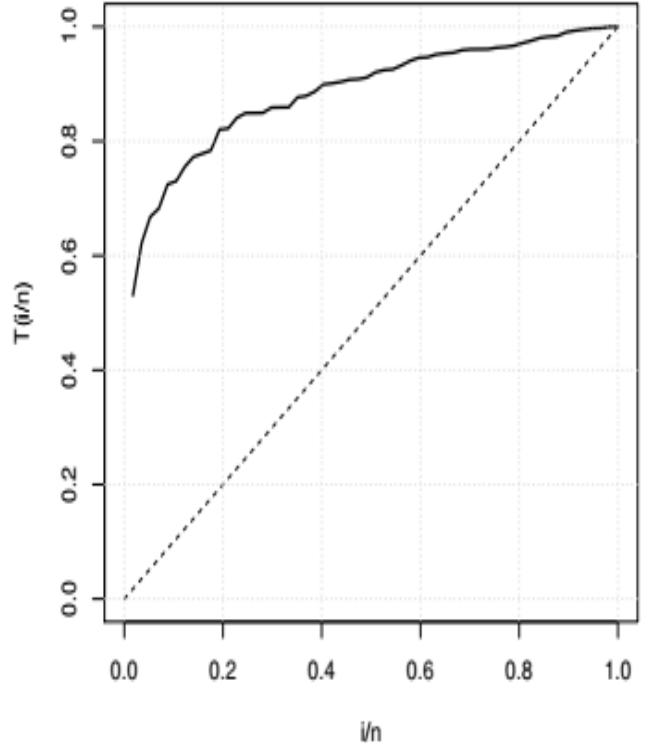

Figure 7: TTT plot for data set 1.

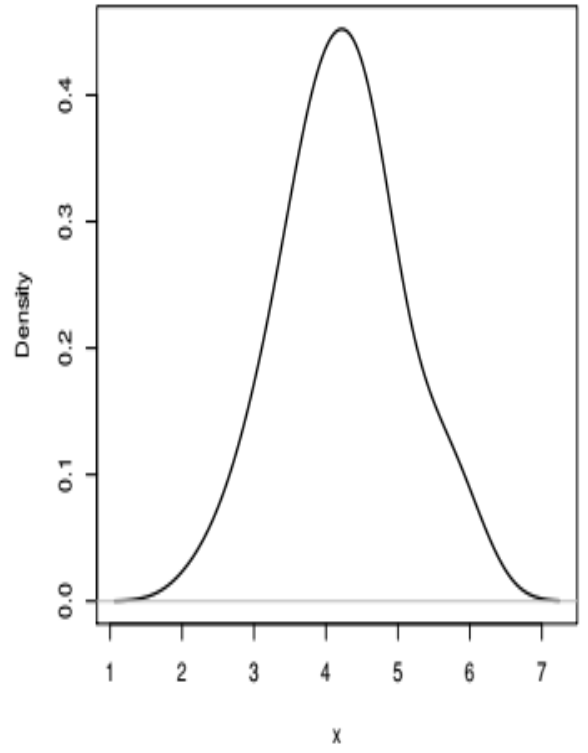

Figure 8: Gaussian kernel density estimation for data set 1 .

The first data set (Crowder et. al [21]) refers to the failure stresses of single carbon fibers (length $1 \mathrm{~mm})$. The data are: $2.247,2.64,2.842,2.908,3.099,3.126,3.245,3.328,3.355,3.383,3.572,3.581,3.681,3.726,3.727,3.728,3.783$, $3.785,3.786,3.896,3.912,3.964,4.05,4.063,4.082,4.111,4.118,4.141,4.216,4.251,4.262,4.326,4.402,4.457$, $4.466,4.519,4.542,4.555,4.614,4.632,4.634,4.636,4.678,4.698,4.738,4.832,4.924,5.043,5.099,5.134,5.359$, $5.473,5.571,5.684,5.721,5.998,6.06$. A summary of these data is:

$$
n=57, \bar{x}=4.2350, s=0.8352, \text { skewness }=0.0710, \text { kurtosis }=2.7098 \text {. }
$$

Based on the figures in table 1, we conclude that all the models provide the adequate fit, whereas that EW and GEE provides the best fit followed by WEEP and WLLP. The summary statistics and figure indicate that the first data set is approximately symmetric. This indicates that the new family of distributions has the ability to fit data set with symmetric shape. The P-P plot given in Figure 13 also supports the results of Table 3. 


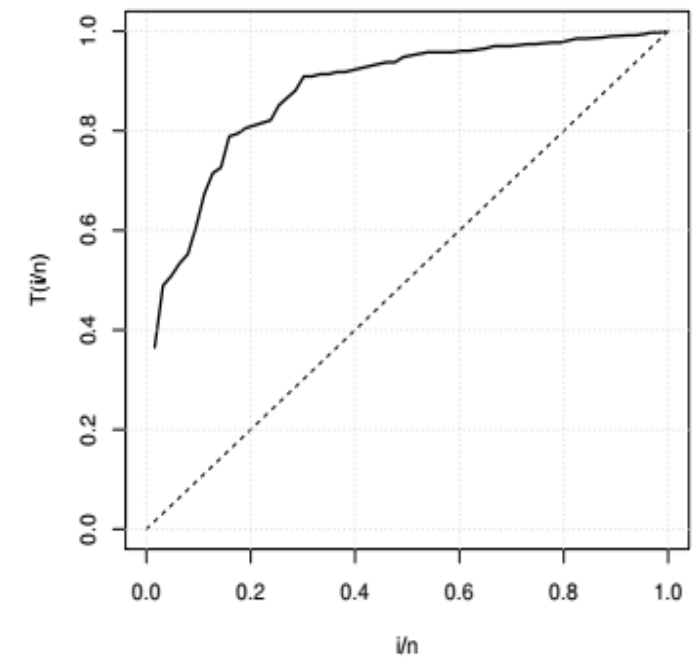

Figure 9: TTT plot for data set 2.

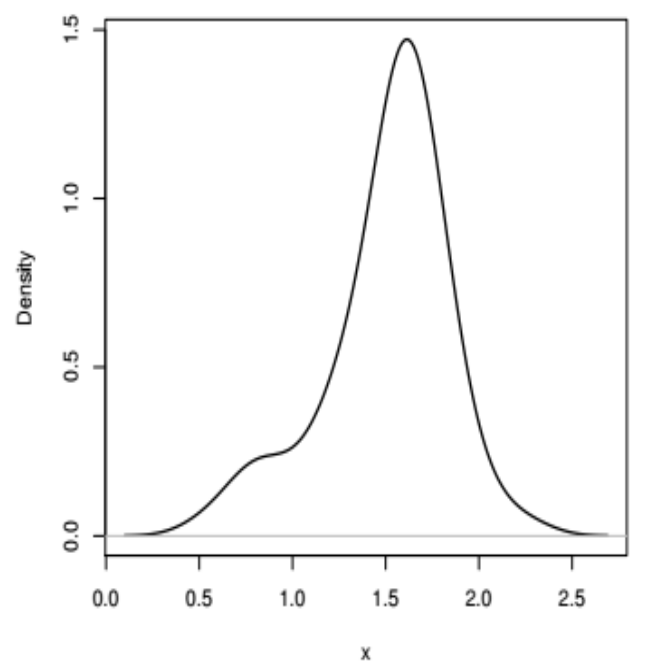

Figure 10: Gaussian kernel density estimation for data set 2 .

Table 3: MLEs, their standard errors (in parentheses) and goodness of fit measures for the first data

set.

\begin{tabular}{|c|c|c|c|c|c|c|c|}
\hline \multirow{2}{*}{$\begin{array}{l}\text { Distribution } \\
\qquad \operatorname{WGP}(a, \alpha, b)\end{array}$} & \multicolumn{3}{|c|}{ Estimates } & \multirow{2}{*}{$\begin{array}{c}-\ell \\
71.972\end{array}$} & \multirow{2}{*}{$\begin{array}{c}\text { AIC } \\
149.944\end{array}$} & \multirow{2}{*}{$\begin{array}{c}\mathrm{K}-\mathrm{S} \\
0.119\end{array}$} & \multirow{2}{*}{$\begin{array}{r}\text { P-value } \\
0.366\end{array}$} \\
\hline & 18.626 & 0.669 & 0.239 & & & & \\
\hline & $(1.614)$ & $(0.384)$ & $(0.242)$ & & & & \\
\hline $\operatorname{WLLP}(c, \alpha, s)$ & $\begin{array}{c}0.850 \\
(0.036)\end{array}$ & $\begin{array}{c}5.779 \\
(1.082)\end{array}$ & $\begin{array}{c}4.316 \\
(0.120)\end{array}$ & 71.440 & 148.880 & 0.0836 & 0.789 \\
\hline $\operatorname{WEEP}(\beta, \alpha, \lambda)$ & $\begin{array}{c}73.665 \\
(1.403)\end{array}$ & $\begin{array}{c}0.718 \\
(0.217)\end{array}$ & $\begin{array}{c}1.090 \\
(0.294)\end{array}$ & 70.368 & 146.736 & 0.0817 & 0.812 \\
\hline $\operatorname{GEE}(\alpha, \beta, \delta)$ & $\begin{array}{c}17.195 \\
(42.158)\end{array}$ & $\begin{array}{c}33.7264 \\
(10.8439)\end{array}$ & $\begin{array}{c}0.2234 \\
(0.4127)\end{array}$ & 70.656 & 147.313 & 0.0609 & 0.975 \\
\hline $\operatorname{EW}(c, \alpha, \lambda)$ & $\begin{array}{c}3.4586 \\
(1.2814)\end{array}$ & $\begin{array}{c}2.6978 \\
(2.1688)\end{array}$ & $\begin{array}{c}3.7682 \\
(0.7208)\end{array}$ & 70.049 & 146.098 & 0.059 & 0.982 \\
\hline
\end{tabular}

The second data set corresponds to strengths of $15 \mathrm{~cm}$ fibres reported by Smith and Naylor (1987). The summary statistics of the second data set are:

$$
n=46, \bar{x}=1.13, s=0.2713 \text {, skewness }=0.7935 \text { and } \text { kurtosis }=0.5995 \text {. }
$$

From figures in table 3, we conclude that WGP and WEEP models provide the adequate fit, whereas that GEE do not provide the god fit. The summary statistics and figure indicate that the first data set is approximately left skewed. This indicates that the new family of distributions can fit data set with left skewed characteristic. The P-P plot given in figure 14 also supports the results of table 3

Table 4: MLEs, their standard errors (in parentheses) and goodness of fit measures for the second data set.

\begin{tabular}{|c|c|c|c|c|c|c|c|}
\hline Distribution & & Estimates & & $-\ell$ & $\mathrm{AIC}$ & $\mathrm{K}-\mathrm{S}$ & P-value \\
\hline $\mathrm{WGP}(\mathrm{a}, \alpha, \mathrm{b})$ & $\begin{array}{c}0.7325 \\
(1.3366)\end{array}$ & $\begin{array}{c}4.6132 \\
(5.8305)\end{array}$ & $\begin{array}{c}3.5440 \\
(10.130)\end{array}$ & 13.740 & 33.480 & 0.134 & 0.207 \\
\hline $\operatorname{WLLP}(c, \alpha, s)$ & $\begin{array}{c}1.9295 \\
(0.5286)\end{array}$ & $\begin{array}{c}2.7085 \\
(0.8715)\end{array}$ & $\begin{array}{c}1.5454 \\
(0.0374)\end{array}$ & 14.149 & 34.299 & 0.141 & 0.166 \\
\hline $\operatorname{WEEP}(\beta, \alpha, \lambda)$ & $\begin{array}{c}0.6057 \\
(0.0320)\end{array}$ & $\begin{array}{c}5.2402 \\
(0.7194)\end{array}$ & $\begin{array}{c}0.2471 \\
(1.8881)\end{array}$ & 13.734 & 33.469 & 0.134 & 0.208 \\
\hline $\operatorname{GEE}(\alpha, \beta, \delta)$ & $\begin{array}{c}18.814 \\
(20.375)\end{array}$ & $\begin{array}{l}24.6684 \\
(7.0427)\end{array}$ & $\begin{array}{c}0.4336 \\
(0.3939)\end{array}$ & 24.509 & 55.0189 & 0.2186 & 0.0048 \\
\hline $\operatorname{EW}(c, \alpha, \lambda)$ & $\begin{array}{c}7.2846 \\
(1.7069)\end{array}$ & $\begin{array}{c}0.6712 \\
(0.2488)\end{array}$ & $\begin{array}{c}1.7180 \\
(0.0860)\end{array}$ & 14.675 & 35.351 & 0.146 & 0.135 \\
\hline
\end{tabular}


The third data set describes the 101 stress-rupture lives of 49 kevlar epoxy strands, which were subjected to constant sustained pressure at the 90 stress level until all had failed, so that we have complete data with exact times of failure. The failure times (in hours) are given in Cooray and Ananda (2008). The summary statistics of the first data set are: $n=101, \bar{x}=1.0248, s=1.1193$, skewness $=3.00172$ and kurtosis $=13.7089$.

From the figures in table 5, we verify that WGLLP, WEEP and WGP provides the best fit. A close look at the summary statistics and figure 15 indicate that the third data are right skewed. So, the proposed family has the ability to fit right skewed data. The P-P plot in figure also supports the result in table 5.

Table 5: MLEs, their standard errors (in parentheses) and goodness of fit measures for the third data set.

\begin{tabular}{|c|c|c|c|c|c|c|c|}
\hline \multicolumn{2}{|l|}{ Distribution } & \multicolumn{2}{|l|}{ Estimates } & \multirow{2}{*}{$\begin{array}{c}-\ell \\
104.279\end{array}$} & \multirow{2}{*}{$\begin{array}{c}\text { AIC } \\
214.558\end{array}$} & \multirow{2}{*}{$\begin{array}{r}\text { K-S } \\
0.081\end{array}$} & \multirow{2}{*}{$\begin{array}{l}\text { P-value } \\
0.509\end{array}$} \\
\hline $\mathrm{WGP}(\mathrm{a}, \alpha, \mathrm{b})$ & 0.7325 & 4.6132 & 3.5440 & & & & \\
\hline & $(1.3366)$ & $(5.8305)$ & $(10.130)$ & & & & \\
\hline $\operatorname{WLLP}(c, \alpha, s)$ & $\begin{array}{c}1.9295 \\
(0.5286)\end{array}$ & $\begin{array}{c}2.7085 \\
(0.8715)\end{array}$ & $\begin{array}{c}1.5454 \\
(0.0374)\end{array}$ & 102.398 & 210.797 & 0.078 & 0.561 \\
\hline $\operatorname{WEEP}(\beta, \alpha, \lambda)$ & $\begin{array}{c}0.6057 \\
(0.0320)\end{array}$ & $\begin{array}{c}5.2402 \\
(0.7194)\end{array}$ & $\begin{array}{c}0.2471 \\
(1.8881)\end{array}$ & 103.936 & 213.873 & 0.079 & 0.544 \\
\hline $\operatorname{GEE}(\alpha, \beta, \delta)$ & $\begin{array}{c}18.8149 \\
(20.3751)\end{array}$ & $\begin{array}{l}24.6684 \\
(7.0427)\end{array}$ & $\begin{array}{c}0.4336 \\
(0.3939)\end{array}$ & 103.936 & 213.873 & 0.079 & 0.544 \\
\hline $\mathrm{EW}(c, \alpha, \lambda)$ & $\begin{array}{c}7.2846 \\
(1.7069)\end{array}$ & $\begin{array}{c}0.6712 \\
(0.2488)\end{array}$ & $\begin{array}{c}1.7180 \\
(0.0860)\end{array}$ & 102.787 & 211.574 & 0.084 & 0.468 \\
\hline
\end{tabular}

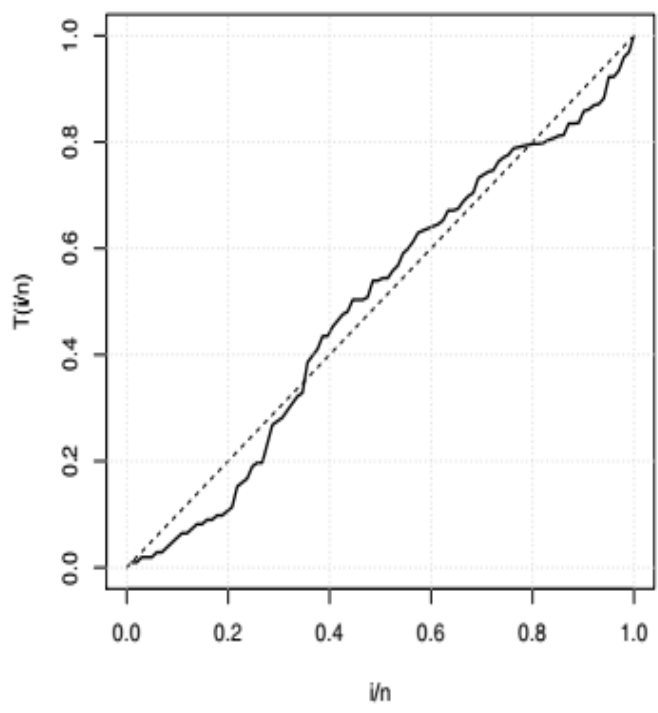

Figure 11: TTT plot for data set 3.

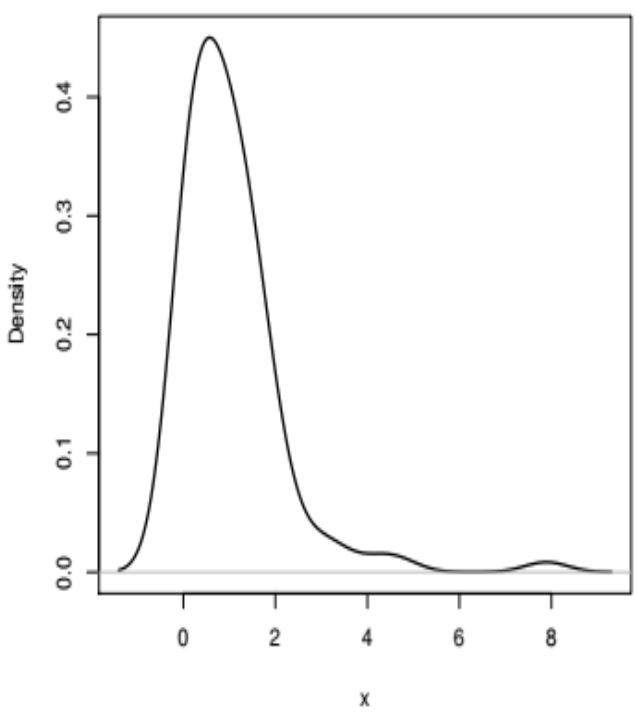

Figure 12: Gaussian kernel density estimation for data set 3 . 

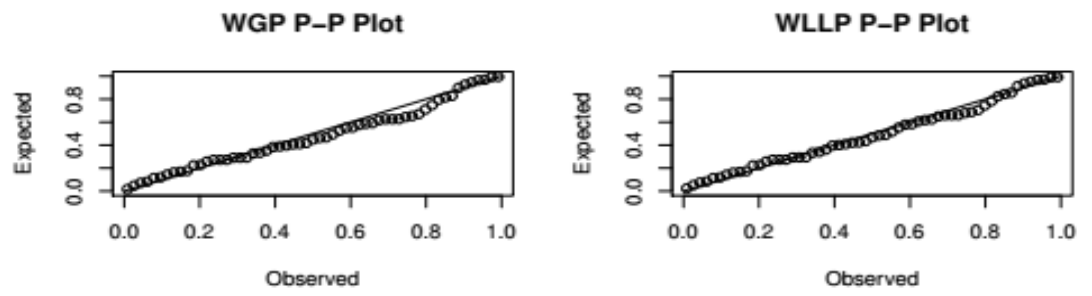

WEEP P-P Plot

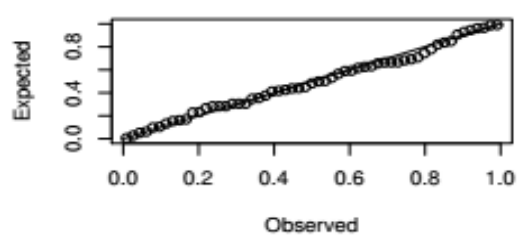

EW P-P Plot

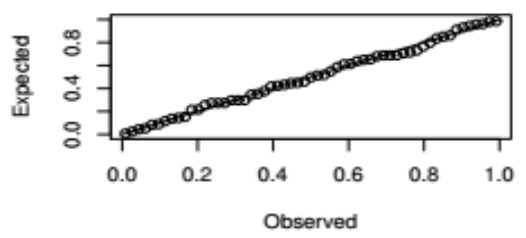

GEE P-P Plot

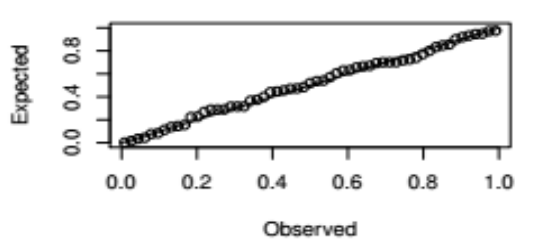

Figure 13: P-P plots of WGP, WLLP, WEEP, GEE and EW models for data set 1.

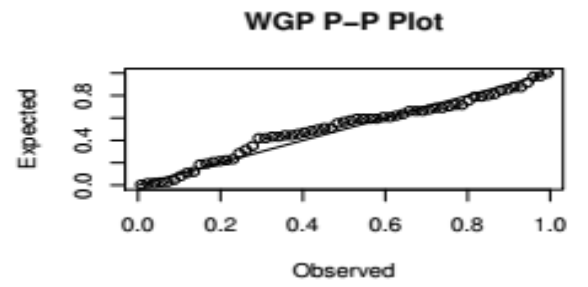

WEEP P-P Plot

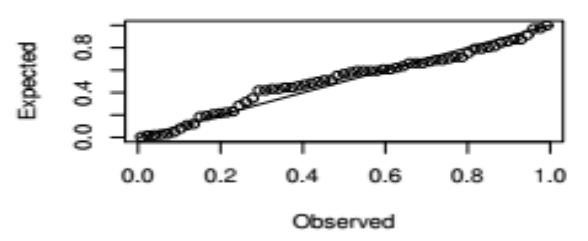

EW P-P Plot

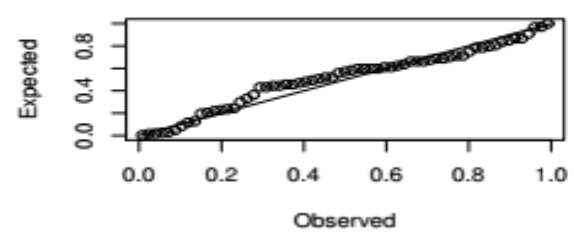

WLLP P-P Plot

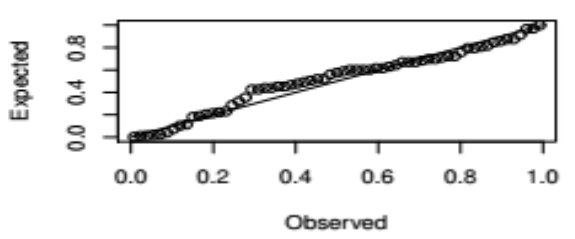

GEE P-P Plot

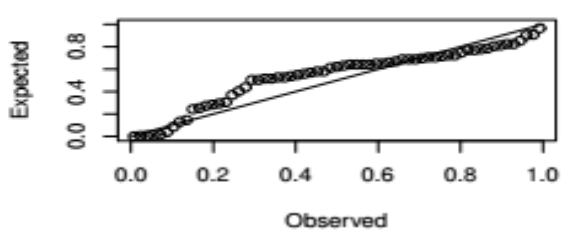

Figure 14: P-P plots of WGP, WLLP, WEEP, GEE and EW models for data set 2. 


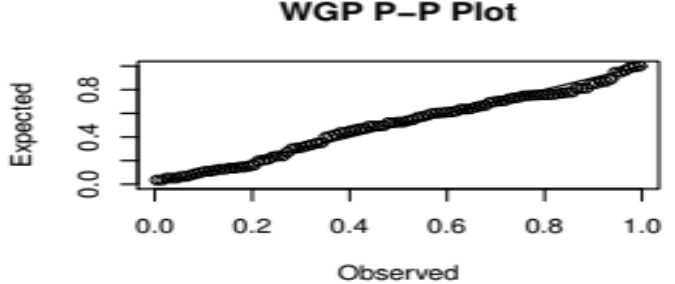

WEEP P-P Plot

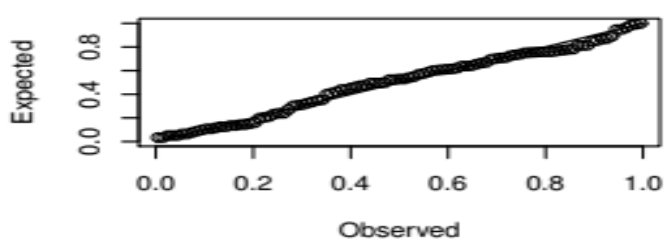

EW P-P Plot

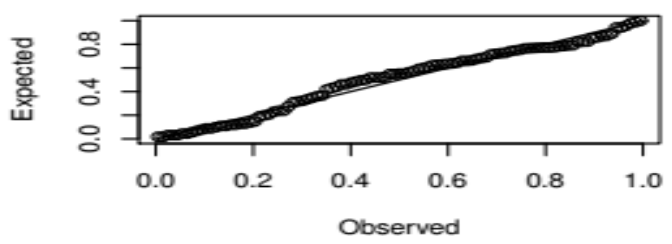

WLLP P-P Plot

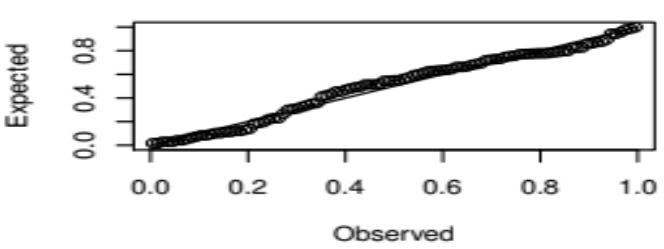

GEE P-P Plot

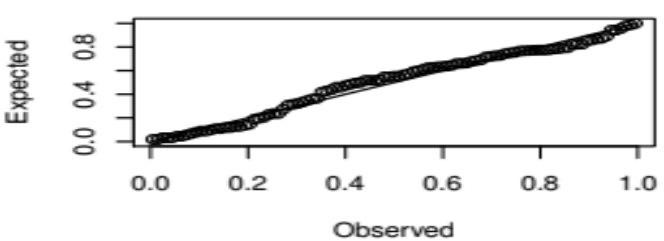

Figure 15: P-P plots of WGP, WLLP, WEEP, GEE and EW models for data set 3.

\section{Conclusions}

In this paper, we present a new Weibull-G Poisson (WGP) family of distributions, which extends the Weibull-G family by adding one extra shape parameter. Some mathematical properties of the new family including explicit expressions for the ordinary and incomplete moments, quantile and generating functions, mean deviations, entropies and order statistics are provided. The model parameters are estimated by maximum likelihood and the observed information matrix is determined. We perform a Monte Carlo simulation study to assess the finite sample behavior of the maximum likelihood estimators. We prove empirically by means of three real data sets that some special models of the WGP family can give better fits than other models generated from well-known families.

\section{References}

1. Aarset, M. V. (1987). How to identify bathtub hazard rate. IEEE Trans. Reliab., 36 106-108.

2. Afify, A. Z., Alizadeh, M., Yousof, H. M., Aryal, G. and Ahmad, M. (2016a). The transmuted geometric-G family of distributions: theory and applications, Pakistan Journal of Statistics, 32(2), 139-160.

3. Afify, A. Z., Cordeiro, G. M., Yousof, H. M. Alzaatreh, A., and Nofal, Z. M. (2016b). The Kumaraswamy transmuted-G family of distributions: properties and applications, Journal of Data Science, 14, 245-270.

4. Alizadeh, M., Cordeiro, G. M. and Brito, E., (2015). The beta Marshall-Olkin family of distributions. Journal of Statistical Distributions and Applications, 2:4, 18-page.

5. Alizadeh, M., Rasekhi, M., Yousof, H. M. and Hamedani G. G. (2018). The transmuted Weibull G family of distributions. Hacettepe Journal of Mathematics and Statistics, 47, 1-20.

6. Altun, E., Yousof, H. M., Chakraborty, S. and Handique, L. (2018a). Zografos-Balakrishnan Burr XII distribution: regression modeling and applications. International Journal of Mathematics and Statistics, 19(3), 46-70.

7. Altun, E., Yousof, H. M. and Hamedani, G. G. (2018b). A new log-location regression model with influence diagnostics and residual analysis. Facta Universitatis, Series: Mathematics and Informatics, 33(3), 417-449.

8. Aryal, G. R. and Yousof, H. M. (2017). The exponentiated generalized-G Poisson family of distributions. Economic Quality Control, 32, 1-17.

9. Alizadeh, M., Ghosh, I., Yousof, H. M., Rasekhi, M. and Hamedani G. G. (2017). The generalized odd generalized 
exponential family of distributions: properties, characterizations and applications. Journal of Data Science, 15, 443-466.

10. Basu, B., Tiwari, D., Kundu, D., and Prasad, R. (2009). Is Weibull distribution the most appropriate statistical strength distribution for brittle materials? Ceramics International, 35, 237-246.

11. Barlow, R. E. and Campo, R. A. (1975). Total time on test processes and applications to failure data analysis. In: R.E. Barlow, J.B. Fussel, and N.D. Singpurwalla (eds.), Reliability and Fault Tree Analysis, Society for Industrial and Applied Mathematics, Philadelphia, 451-481.

12. Bourguignon, M., Silva, R. B. and Cordeiro, G. M. (2014). The Weibull-G family of probability distributions. J. Data Sci., 12, 53-68.

13. Brito, E., Cordeiro, G. M., Yousof, H. M., Alizadeh, M. and Silva, G. O. (2017). Topp-Leone Odd Log-Logistic Family of Distributions, Journal of Statistical Computation and Simulation, 87(15), 3040-3058.

14. Cordeiro, G. M., Afify, A. Z., Ortega, E. M. M., Suzuki, A. K. and Mead, M. E. (2019).

The odd Lomax generator of distributions: properties, estimation and applications. Journal of Computational and Applied Mathematics, 347, 222-237.

15. Cordeiro, G. M., Ortega, E. M. M. and da Cunha, D. C. C. (2013). The exponentiated generalized class of distributions. J. Data Sci., 11, 1-27.

16. Cordeiro, G. M. and de Castro, M. (2011). A new family of generalized distributions. Journal of Statistical Computation and Simulation, 81, 883-898.

17. Cordeiro, G. M., Afify, A. Z., Yousof, H. M., Pescim, R. R. and Aryal, G. R. (2017). The exponentiated Weibull$\mathrm{H}$ family of distributions: theory and applications. Mediterranean Journal of Mathematics, 14, 1-22.

18. Cordeiro, G. M., Yousof, H. M., Ramires, T. G. and Ortega, E. M. M. (2018). The Burr XII system of densities: properties, regression model and applications. Journal of Statistical Computation and Simulation, 88(3), $432-456$.

19. Cooray, K. and Ananda, M. M. A. (2008). A generalization of the half-normal distribution with applications to lifetime data. Communications in Statistics- Theory Methods, 37, 1323-1337.

20. Crowder, M. J., Kimber, A. C., Smith, R. L. and Sweeting, T. J. (1991). The statistical analysis of reliability data. Chapman and Hall, London.

21. Drobinski, P., Corentin Coulais, C. and Jourdier, B. (2015). Surface Wind-Speed Statistics Modeling: Alternatives to the Weibull Distribution and Performance Evaluation. Boundary-Layer Meteorology, 1, 97-123.

22. Eugene, N., Lee, C. and Famoye, F. (2002). Beta-normal distribution and its applications. Communications in Statistics-Theory and Methods, 31, 497-512.

23. Gad, A. M., Hamedani, G. G., Salehabadi, S. M. and Yousof, H. M. (2019). The Burr XII-Burr XII distribution: mathematical properties and characterizations. Pakistan Journal of Statistics, 35(3), 229-248.

24. Hamedani G. G., Altun, E, Korkmaz, M. C., Yousof, H. M. and Butt, N. S. (2018). A new extended G family of continuous distributions with mathematical properties, characterizations and regression modeling. Pak. J. Stat. Oper. Res., 14(3), 737-758.

25. Hamedani G. G. Rasekhi, M., Najib, S. M., Yousof, H. M. and Alizadeh, M., (2019). Type II general exponential class of distributions. Pak. J. Stat. Oper. Res., XV (2), 503-523.

26. Hamedani G. G. Yousof, H. M., Rasekhi, M., Alizadeh, M., Najibi, S. M. (2017). Type I general exponential class of distributions. Pak. J. Stat. Oper. Res., XIV (1), 39-55.

27. Ibrahim, M. (2020a). The generalized odd log-logistic Nadarajah Haghighi distribution: statistical properties and different methods of estimation. Journal of Applied Probability and Statistics, forthcoming.

28. Ibrahim, M. (2020b). The compound Poisson Rayleigh Burr XII distribution: properties and applications. Journal of Applied Probability and Statistics, forthcoming.

29. Ibrahim, M., Altun, E. and Yousof, H. M. (2020). A new distribution for modeling lifetime data with different methods of estimation and censored regression modeling. Statistics, Optimization and Information Computing, forthcoming.

30. Ibrahim, M., Yadav, A. S. Yousof, H. M., Goual, H. and Hamedani, G. G. (2019). A new extension of Lindley distribution: modified validation test, characterizations and different methods of estimation, Communications for Statistical Applications and Methods, 26(5), 473-495.

31. Korkmaz, M. C., Alizadeh, M., Yousof, H. M. and Butt, N. S. (2018a). The generalized odd Weibull generated family of distributions: statistical properties and applications. Pak. J. Stat. Oper. Res., 14(3), 541-556.

32. Korkmaz, M. C., Altun, E., Yousof, H. M. and Hamedani G. G. (2019). The Odd Power Lindley Generator of Probability Distributions: Properties, Characterizations and Regression Modeling, International Journal of Statistics and Probability, 8(2), 70-89.

33. Korkmaz, M. C., Yousof, H. M., Hamedani G. G. and Ali, M. M. (2018b). The Marshall-Olkin generalized-G 
Poisson family of distributions, Pakistan Journal of Statistics, 34(3), 251-267.

34. Mansour, M., Yousof, H. M., Shehata, W. A. M. and Ibrahim, M. (2020). A new two parameter Burr XII distribution: properties,copula, different estimation methods and modeling acute bone cancer data, Journal of Nonlinear Science and Applications, forthcoming.

35. Nascimento, A. D. C., Silva, K. F., Cordeiro, G. M., Alizadeh, M. and Yousof, H. M. (2019). The odd NadarajahHaghighi family of distributions: properties and applications. Studia Scientiarum Mathematicarum Hungarica, $56(2), 1-26$.

36. Nofal, Z. M., Afify, A. Z., Yousof, H. M. and Cordeiro, G. M. (2017). The generalized transmuted-G family of distributions. Communications in Statistics-Theory and Methods, 46, 4119-4136.

37. Pak-poy, P. G. (1964). The use and limitation of the Poisson distribution in road traffic. Australian Road Research Board (ARRB) Conference, 2nd, Melbourne.

38. Sen, S., Korkmaz, M. C. and Yousof, H. M. (2018). The quasi xgamma-Poisson distribution. Theory and Applications of Statistics and Information, 18(3), 65-76.

39. Smith, R. L. and Naylor, J. C. (1987). A comparison of maximum likelihood and Bayesian estimators for the threeparameter Weibull distribution. Appl. Statist., 36, 358-369.

40. Yousof, H. M., Afify, A. Z., Alizadeh, M., Butt, N. S., Hamedani, G. G. and Ali, M. M. (2015). The transmuted exponentiated generalized-G family of distributions. Pak.j.stat.oper.res., 11, 441-464.

41. Yousof, H. M., Afify, A. Z., Alizadeh, M., Hamedani G. G., Jahanshahi, S. M. A. and Ghosh, I. (2018a). The generalized transmuted Poisson-G family of Distributions. Pak. J. Stat. Oper. Res., 14 (4), 759-779.

42. Yousof, H. M., Afify, A. Z., Alizadeh, M., Nadarajah, S., Aryal, G. R. and Hamedani, G. G. (2018b). The MarshallOlkin generalized-G family of distributions with Applications, STATISTICA, 78(3), 273- 295.

43. Yousof, H. M., Alizadeh, M., Jahanshahi and, S. M. A., Ramires, T. G., Ghosh, I. and Hamedani G. G. (2017a). The transmuted Topp-Leone $\mathrm{G}$ family of distributions: theory, characterizations and applications, Journal of Data Science. 15, 723-740.

44. Yousof, H. M., Altun, E., Ramires, T. G., Alizadeh, M. and Rasekhi, M. (2018c). A new family of distributions with properties, regression models and applications, Journal of Statistics and Management Systems, 21(1), 163188.

45. Yousof, H. M., Butt, N. S., Alotaibi, R., Rezk, H. R., Alomani, G. A. and Ibrahim, M. (2019). A new compound Fréchet distribution for modeling breaking stress and strengths data. Pak. J. Stat. Oper. Res., 15 (4), 1017-1035.

46. Yousof, H. M., Rasekhi, M., Afify, A. Z., Alizadeh, M., Ghosh, I. and Hamedani G. G. (2017b). The beta WeibullG family of distributions: theory, characterizations and applications, Pakistan Journal of Statistics, 33, 95-116.

47. Yousof, H. M., Majumder, M., Jahanshahi, S. M. A., Ali, M. M. and Hamedani G. G. (2018d). A new Weibull class of distributions: theory, characterizations and applications, Journal of Statistical Research of Iran, 15, 45-83.

\section{Appendix A}

The elements of the observed matrix $J(\Theta)$ are given below:

$$
\begin{gathered}
U_{\theta \theta}=\frac{-n}{\theta^{2}}-\frac{n e^{\theta}\left(e^{\theta}-1\right)-n e^{2 \theta}}{\left(e^{\theta}-1\right)^{2}}, U_{\theta \alpha}=\sum_{i=0}^{n} a_{i}, U_{\theta \phi}=\sum_{i=0}^{n} b_{i}, \\
U_{\alpha \alpha}=\frac{-n}{\alpha^{2}} \sum_{i=0}^{n}\left[\partial d_{i} / \partial \alpha\right]+\theta \sum_{i=0}^{n}\left[\partial a_{i} / \partial \alpha\right], \\
U_{\alpha \psi}=\sum_{i=0}^{n} \frac{G^{\prime}\left(x_{i} ; \phi\right)}{G\left(x_{i} \phi\right)}+\sum_{i=0}^{n} \frac{G^{\prime}\left(x_{i} ; \phi\right)}{\bar{G}\left(x_{i} ; \phi\right)}-\sum_{i=0}^{n}\left[\partial d_{i} / \partial \phi\right]+\theta \sum_{i=0}^{n}\left[\partial a_{i} / \partial \phi\right]
\end{gathered}
$$

and

$$
\begin{aligned}
& U_{\phi_{k} \phi_{k}}=\sum_{i=0}^{n} \frac{g\left(x_{i} ; \phi\right) g^{\prime \prime}\left(x_{i} ; \phi\right)-\left[g^{\prime}\left(x_{i} ; \phi\right)\right]^{2}}{g\left(x_{i} ; \phi\right)^{2}}+(\alpha-1) \sum_{i=0}^{n} \frac{G\left(x_{i} \phi\right) G^{\prime \prime}\left(x_{i} \phi\right)-\left[G^{\prime}\left(x_{i} ; \phi\right)\right]^{2}}{G\left(x_{i} ; \phi\right)^{2}} \\
& +(\alpha+1) \sum_{i=0}^{n} \frac{\bar{G}(x ; \phi) G^{\prime \prime}\left(x_{i} ; \phi\right)+\left[G^{\prime}\left(x_{i} ; \phi\right)\right]^{2}}{\bar{G}(x ; \phi)^{2}}-\sum_{i=0}^{n}\left[\partial t_{i} / \partial \phi\right]+\theta \sum_{i=0}^{n}\left[\partial b_{i} / \partial \phi\right] .
\end{aligned}
$$

where $g^{\prime \prime}\left(x_{i} ; \phi\right)=\partial^{2} g\left(x_{i} ; \phi\right) / \partial \phi_{k}^{2}$ and $G^{\prime \prime}\left(x_{i} ; \phi\right)=\partial^{2} G\left(x_{i} ; \phi\right) / \partial \phi_{k}^{2}$. 